\title{
Erratum to: Hypericum species in the Páramos of Central and South America: a special focus upon $H$. irazuense Kuntze ex N. Robson
}

\author{
Sara Crockett • Marianne Eberhardt • Olaf Kunert • Wolfgang Schühly
}
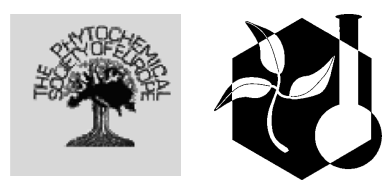

Published online: 7 December 2017

(C) Springer Science+Business Media B.V. 2017

Erratum to: Phytochem Rev (2010) 9:255-269

DOI 10.1007/s11101-009-9148-2

In the original publication, the country name was published incorrectly as "Columbia" throughout the article. However, the country name should read as "Colombia".

The online version of the original article can be found under doi:10.1007/s11101-009-9148-2.

S. Crockett $(\bowtie) \cdot$ M. Eberhardt · W. Schühly

Institute of Pharmaceutical Sciences, Pharmacognosy,

Karl-Franzens-Universität Graz, Universitätsplatz 4,

8010 Graz, Austria

e-mail: sara.crockett@uni-graz.at

O. Kunert

Institute of Pharmaceutical Sciences, Pharmaceutical

Chemistry, Karl-Franzens-Universität Graz,

Universitätsplatz 1, $8010 \mathrm{Graz}$, Austria 